\title{
In Vivo Damage of Rat Lungs by Oxygen Metabolites
}

\author{
Kent J. Johnson, Joseph C. Fantone III, Jerry Kaplan, and Peter A. Ward, \\ Departments of Pathology and Physiology, University of Connecticut Health \\ Center, Farmington, Connecticut 06032; Department of Pathology, University of \\ Michigan Medical School, Ann Arbor, Michigan 48109
}

\begin{abstract}
A в S T R A C T The intrapulmonary instillation into rat lung of enzymes that generate oxygen metabolites results in acute lung injury. The injection of xanthine oxidase and xanthine produces acute lung injury that, in the presence of superoxide dismutase, but not in the presence of catalase, can be significantly diminished, suggesting that $\mathrm{O}_{2}^{-}$has the capacity to injure the lung. Instillation of a generator of $\mathrm{H}_{2} \mathrm{O}_{2}$, namely glucose oxidase, will, in sufficient quantities, produce acute injury that is not neutrophil-dependent. When either a low dose of glucose oxidase alone or lactoperoxidase alone is employed, little lung injury occurs. However, instilling the combination of the two enzymes produces severe, acute injury that can be blocked in a dose-dependent manner by catalase, but not by superoxide dismutase. Purified human leukocytic myeloperoxidase, but not horseradish peroxidase, will substitute for lactoperoxidase in the model of lung injury. The lung damaging effects of these enzymes cannot be attributed to the presence of contaminating proteases. Acute lung injury produced by the instillation of glucose oxidase and lactoperioxidase progresses to interstitial fibrosis. These studies represent a direct application of generators of oxygen metabolites to the in vivo induction of lung injury. The data suggest that rat lung is susceptible to injury by a variety of oxygen metabolites, including $\mathrm{O}_{2}^{-}, \mathrm{H}_{2} \mathrm{O}_{2}$ and its lactoperoxidase or myeloperoxidase-produced derivatives. The studies also indicate that lung injury produced by oxygen metabolites can result in interstitial pulmonary fibrosis.
\end{abstract}

\section{INTRODUCTION}

Considerable evidence has accumulated over recent years suggesting that oxygen metabolites may be responsible for acute injury of cells and tissues. There is much speculation that the free radicals derived from molecular oxygen represent a common etiology in injury produced by exposure to toxic levels of oxygen $(1,2)$, to antineoplastic drugs (3), herbicides and other

Received for publication 21 July 1980 and in revised form 23 December 1980. toxins (4), and the injury produced in leukocytedependent reactions $(5-14)$. In vitro, oxygen-free radicals $\left(\mathrm{O}_{2}^{-}, \cdot \mathrm{OH}\right)$ and other metabolites $\left({ }^{1} \mathrm{O}_{2}, \mathrm{H}_{2} \mathrm{O}_{2}, \mathrm{HOCl}\right)$ are capable of inflicting cytotoxic damage on isolated cells $(5-12)$. This has been clearly demonstrated for in vitro systems in which the free radicals are enzymatically derived using xanthine oxidase and myeloperoxidase and the concentrations of specific radicals altered by the addition of superoxide dismutase, catalase, and specific radical scavengers (e.g., mannitol, xanthine, thiourea, histidine) (6-8). More compelling evidence for the role of oxygen metabolites in inducing tissue injury has been provided by recent investigations in which inhibitors of specific free radicals have been shown to block the cytotoxic effects of neutrophils $(5,10,11)$, activated macrophages (9), and T lymphocytes (12). It appears that, depending on the experimental constraints imposed on a given in vitro system, the degree and specificity of injury induced by specific free radicals can be altered.

Despite the current advances in our understanding of the role of oxygen metabolites and free radicals in initiating cytotoxic damage and tissue injury, there remains a paucity of evidence of a direct nature to support the conclusions derived from the in vitro data. Recently, using inhibitors, two groups have reported the suppression of the reverse passive Arthus reaction in the skin of rats by systemic administration of superoxide dismutase $(13,14)$, thereby, implicating the role of $\mathrm{O}_{2}^{-}$in immune complex mediated acute inflammation. This current study was undertaken in an attempt to examine in vivo the capacity of oxygen-derived free radicals to initiate tissue injury. In this report, we provide direct evidence that enzymes capable of generating oxygen metabolites will cause significant, acute tissue damage in rat lungs. Under certain conditions, the eventual outcome is extensive interstitial pulmonary fibrosis. The data derived by examining the effects of a variety of mixtures that will generate oxygen metabolites as well as the use of inhibitors of these products suggest that the rat lung is susceptible to injury that can be induced by a variety of oxygen-derived metabolites. 


\section{METHODS}

Animals. Young adult 250-g male Long Evans rats (Charles River Breeding Laboratories, Wilmington, Mass.) were used in these studies. Under Ketamine anesthesia, tracheosotomy incisions were performed and reagents in a volume of 0.25 $\mathrm{ml}$ in phosphate-buffered ( $\mathrm{pH} 7.4$ ) saline were injected into the airways during inspiration via a fine Teflon catheter. Afterwards, the catheter was removed and the incision closed with silk surgical thread.

Pulmonary injury. This was measured quantitatively by methods that have recently been described in detail (14) Briefly, $\sim 1 \mu \mathrm{C}{ }^{125}$ I-rat albumin $(\sim 0.5 \mu \mathrm{g})$ is injected intravenously at time zero, immediately after injection of reactants into the lung. $4 \mathrm{~h}$ later, animals are sacrificed by ether anesthesia and surgical transection of the aorta. Blood is collected and the amount of radioactivity in $1.0 \mathrm{ml}$ assessed. Then, the trachea and mediastinal contents are removed by en block dissection. $10 \mathrm{ml}$ saline is perfused through the right ventricle of the heart and the perfusate allowed to exit from the aortic outlet. Then, the lungs are inflated with buffered formaldehyde, the trachea tied and the heart and thymus removed. The lungs are then quantitated for total radioactivity. Then the ratio of this value to the amount of radioactivity in $1.0 \mathrm{ml}$ blood is calculated as the permeability or "lung injury" value. For animals receiving an intrapulmonary injection of 0.25 $\mathrm{ml}$ saline $4 \mathrm{~h}$ earlier, the permeability value usually lies between 0.24 and 0.34 . The percent inhibition of lung injury by specific inhibitors was calculated as follows:

$$
\% \text { inhibition }=\frac{\left(\begin{array}{l}
\text { enzyme }+ \text { substrate } \\
+ \text { inhibitor permeability value }
\end{array}\right)-\left(\begin{array}{l}
\text { saline } \\
\text { permeability value }
\end{array}\right)}{(\text { enzyme }+ \text { substrate permeability value })-(\text { saline permeability value })} .
$$

Reactants. Glucose oxidase (from Aspergillus niger), lactoperoxidase (from bovine milk), galactose oxidase (from Dactylium dendroides), xanthine oxidase (from bovine milk) and horseradish peroxidase, as well as glucose, galactose and xanthine were all obtained from the Sigma Chemical Co. (St. Louis, Mo.) and were dissolved or diluted in phosphate-buffered saline ( $\mathrm{pH}$ 7.4). When heated, glucose oxidase was held at $60^{\circ} \mathrm{C}$ for $\mathrm{l} \mathrm{h}$ before use. Superoxide dismutase (SOD) ${ }^{1}$ was purchased from Diagnostic Data, Inc. (Mountain View, Calif.). Purified human leukocytic myeloperoxidase was kindly provided by Dr. John Spitznagel (Emory University, Atlanta, Ga.) and was used in an amount of $5 \mathrm{U}$.

The stock solution of glucose oxidase contained $1,200 \mathrm{U} / \mathrm{ml}$; lactoperoxidase was $340 \mathrm{U} / \mathrm{ml}$; xanthine oxidase $25 \mathrm{U} / \mathrm{ml}$, SOD $4,000 \mathrm{U} / \mathrm{mg}$, and catalase $10,000 \mathrm{U} / \mathrm{mg}$ protein. On slab gel electrophoresis, the preparations of SOD and catalase $(50 \mu \mathrm{g}$ being applied to the gel) yielded single bands when stained with Coomassie Blue R250. Xanthine oxidase was desalted by Sephadex G-25 chromatography assayed for activity (15), and dissolved in phosphate-buffered saline $(\mathrm{pH} 7.4)$ at a concentration of between 1-15 U/ml depending on the specific experiment. Specific xanthine oxidase preparations (Results) were pretreated with $5 \mathrm{mM}$ phenylmethyl-sulfonyl fluoride (PMSF) and subsequently dialyzed overnight to abolish serine-protease activity. Subsequent assay for protease activity in the purified preparations showed only background activity.

SOD and catalase (Sigma Chemical Co., crystallized twice) were dissolved in phosphate-buffered (pH 7.4) saline. Reactants were kept at $5^{\circ} \mathrm{C}$, added to a total vol of $0.25 \mathrm{ml}$, maintained at $5^{\circ} \mathrm{C}$, and the mixture immediately injected into the lung. Each mixture was made up individually immediately before injection. Depending on the experiment, the following quantity of each reactant was used: xanthine, $90 \mathrm{nmol}$; xanthine oxidase, $0.2,0.6$, or $2.5 \mathrm{U}$ (determined by the method of Salin and McCord [15] in vitro at $37^{\circ} \mathrm{C}, \mathrm{pH} 7.4,1 \mathrm{U}$ generates $1 \mu \mathrm{mol}$ of $\left.\mathrm{O}_{2}^{-} / \mathrm{min}\right)$; SOD, 2.5-6 mg (10,000-24,000 U); cata-

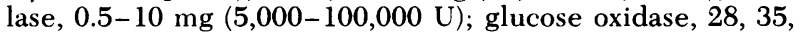
and $70 \mathrm{U}$; lactoperoxidase, $1.7 \mathrm{U}$; galactose oxidase, $20 \mathrm{U}$; glucose, $1 \mathrm{mg}$. Assuming complete substrate use, it can be calculated that the following reaction produced (assuming that no further conversion products would be generated): $90 \mathrm{nmol}$ of $\mathrm{O}_{2}^{-}(2.5 \mu \mathrm{mol} / \mathrm{min}$ generated from $2.5 \mathrm{U}$ xanthine oxidase and $90 \mathrm{nmol}$ xanthine); $6 \mu \mathrm{mol} \mathrm{H}_{2} \mathrm{O}_{2}$ from glucose oxi-

${ }^{1}$ Abbreviations used in this paper: PMSF, phenylmethylsulfonyl fluoride; SOD, superoxide dismutase. dase or galactose oxidase and glucose or galactose (generated at the rate of $25 \mu \mathrm{mol} / \mathrm{min}$ ). In the preparation of glucose oxidase, $25 \mathrm{U}$ of this enzyme contained $\sim 0.7 \mathrm{U}$ catalase, implying a 36-fold excess of glucose oxidase. It can be calculated that at the rate of generation of $\mathrm{H}_{2} \mathrm{O}_{2}$ by glucose oxidase, 25 $\mu \mathrm{mol} / \mathrm{min}$, the rate of breakdown by contaminating catalase would be $0.7 \mu \mathrm{mol} / \mathrm{min}$. To determine if the calculated theoretical rate of formation of $\mathrm{O}_{2}^{-}$and $\mathrm{H}_{2} \mathrm{O}_{2}$ represent accurate approximation of the experimental conditions, the quantity of $\mathrm{O}_{2}^{-}$and $\mathrm{H}_{2} \mathrm{O}_{2}$ formed in vitro was measured. When xanthine $(45 \mathrm{nmol})$ was reacted with xanthine oxidase $(0.25 \mathrm{U})$ in a total $\mathrm{vol}$ of $1.0 \mathrm{ml}$, the rate of $\mathrm{O}_{2}^{-}$formation was determined by the reduction of ferricytochrome $c$ as described by Salin and $\mathrm{McCord}(15)$. At $37^{\circ} \mathrm{C}, \mathrm{pH} 7.4$, the reaction was virtually complete after $45 \mathrm{~s}$ with $\sim 40 \mathrm{nmol}$ of $\mathrm{O}_{2}^{-}$produced. At $4^{\circ} \mathrm{C}, \mathrm{pH}$ $7.4, \sim 2$ min were required to produce a comparable amount of $\mathrm{O}_{2}^{-}$. Therefore, it appears that after rapid intra-tracheal instillation of xanthine and xanthine oxidase $\mathrm{O}_{2}^{-}$is generated rapidly as the reaction mixture is heated from $4^{\circ} \mathrm{C}$ to the basal temperature of rats $\left(\sim 37^{\circ} \mathrm{C}\right)$. The amount of $\mathrm{H}_{2} \mathrm{O}_{2}$ formed in vitro by the reaction of glucose oxidase $(35 \mathrm{U})$ and 1 $\mathrm{mg}$ glucose in a total vol of $0.3 \mathrm{ml}$ was determined by the formation of ferrithiocyanate complex as described by Thurman et al. (16). At $\mathrm{pH} 7.4$ and $37^{\circ} \mathrm{C}$, the initial rate of formation of $\mathrm{H}_{2} \mathrm{O}_{2}$ was $\sim 650 \mathrm{nmol} / \mathrm{min}$ and the maximum amount present in the reaction mixture was $550 \mathrm{nmol}$ at $2 \mathrm{~min}$ after initiation of the reaction. By $2 \mathrm{~h}, \sim 6 \mu \mathrm{mol}$ of $\mathrm{H}_{2} \mathrm{O}_{2}$ had been formed. This deviation from the theoretical optimum rate of formation of $\mathrm{H}_{2} \mathrm{O}_{2}$ by glucose oxidase can be attributed to the presence of contaminating catalase as well as a change in $\mathrm{pH}$ at which the rates of formation are determined. The theoretical rate of formation of $\mathrm{H}_{2} \mathrm{O}_{2}$ by glucose oxidase was calculated on the basis of $\mathrm{pH} 5.1$, whereas the data presented here was determined by $\mathrm{pH} 7.4$

It is important to emphasize that the calculated and measured reaction rates of formation of the various oxygen metabolites represent theoretical values under in vitro conditions. Since it is not possible to quantitate directly the precise in vivo rate of formation of these reactants, these theoretical calculations serve only as estimates of the relative concentrations of the oxygen metabolites formed in vivo.

For some experiments, the preparations of catalase were chemically inactivated by reduction (with $\beta$-mercaptoethanol) and alkylation (with iodoacetate) according to standard methods (17). The catalase preparation was then dialyzed extensively in phosphate-buffered saline ( $\mathrm{pH}$ 7.4). This preparation retained $<1 \%$ of its ability to enzymatically inactivate 
$\mathrm{H}_{2} \mathrm{O}_{2}$ as compared with the untreated preparation of catalase (18).

Determinations of protease contaminants in enzyme preparations. The presence of nonspecific protease activity in the preparations of xanthine oxidase, glucose oxidase, galactose oxidase, and lactoperoxidase was determined by incubation of $50-\mu$ l aliquots of enzyme with $25 \mu$ l of $\left[\mathrm{U}-{ }^{14} \mathrm{C}\right]-E s$ cherichia coli protein (10-100 $\mu \mathrm{Ci} / \mathrm{mg}$, New England Nuclear, Boston, Mass.) diluted with bovine serum albumin $(0.5 \mathrm{mg} /$ $\mathrm{ml}$ ) at $37^{\circ} \mathrm{C}$ for $20 \mathrm{~min}$. Trichloroacetic acid was added to a final concentration of $5 \%$ and the total soluble counts determined by ${ }^{14} \mathrm{C}$ scintillation with $\sim 80 \%$ efficiency after centrifugation at $10,000 \mathrm{~g}$ for $15 \mathrm{~min}$. When trypsin was used to estimate the sensitivity of this assay, as little as $0.5 \mu \mathrm{g}$ of trypsin resulted in $\sim 75 \%$ solubilization of the total radiolabeled substrate. Negative controls showed less than $10 \%$ solubilization of the substrate.

There was no detectable protease activity in the preparations of lactoperoxidase and glucose oxidase, while galactose oxidase showed minimal protease activity. However, there was substantial detectable protease activity in the xanthine oxidase with as little as $0.02 \mathrm{U}$ of this commercial preparation, causing $\sim 50 \%$ digestion of added radiolabeled substrate.

Neutrophil depletion experiments. Rabbit antibody to rat neutrophils was prepared as described (19). Rats were injected intraperitoneally with $1.5 \mathrm{ml}$ rabbit serum containing the antibody $\sim 12 \mathrm{~h}$ before initiation of the experiment.

Morphological studies. At the time of sacrifice and perfusion of the pulmonary vasculature with saline, the airways were inflated with buffered formaldehyde in the standard manner and then processed routinely for light microscopy.

Statistics. The Students $t$ test was used to compare the lung permeability changes between different animal groups.

\section{RESULTS}

Lung injury produced by xanthine oxidase. Five different experiments (A-E), using different doses of chromatographically desalted xanthine oxidase and various inhibitors, listed in Table I, were carried out to determine if xanthine oxidase would produce products, presumably $\mathrm{O}_{2}^{-}$, that would lead to intrapulmonary injury. As shown in Table I, in experiment $A$, the combination of xanthine and xanthine oxidase produced acute lung injury, as reflected in a sixfold increase in permeability changes within the lung, as compared with the negative (saline) control $(P<0.001)$. That the combination of the enzyme and the substrate was necessary for this result was shown by the failure of xanthine alone or xanthine oxidase alone to cause pulmonary injury (Table I, experiment A). The instillation of these individual components yielded results similar to the effect of saline alone. In experiments B and C, the relationship of the tissue injury to production of $\mathrm{O}_{2}^{-}$was demonstrated by the fact that the presence of $2.5 \mathrm{mg}$ SOD protected the lung, achieving $42 \%$ protection in experiment $\mathrm{B}(P<0.02)$ and $60 \%$ protection in experiment $C(P<0.02)$. When the amount of SOD was increased to $5 \mathrm{mg}$ per injection (experiment $\mathrm{B}$ ), there was only a small increase in inhibition $(67 \%)$ of the permeability change induced by the xanthine-xanthine oxidase system. This suggests that SOD provides incomplete protection of the lung to injury induced by xanthine-xanthine oxidase products. In experiment $D$ it was demonstrated that the acute lung injury could be significantly suppressed $(P<0.01)$ by the simultaneous intrapulmonary injection of SOD $(54 \%$ inhibition of lung injury) but not by catalase (4\% inhibition). In experiment $E$, in which a lower dose of xanthine oxidase was analyzed, SOD achieved $61 \%$ inhibition, whereas catalase was noninhibitory. The combination of the two inhibitors yielded a similar degree of inhibition (65\%), suggesting that lung injury produced by instillation of xanthine oxidase is due directly to $\mathrm{O}_{2}^{-}$and not its enzymatically converted products such as $\mathrm{H}_{2} \mathrm{O}_{2}$ and $\mathrm{OH}$. (20). The inability of SOD to inhibit completely the pulmonary damage may be due to the direct toxic effects of uric acid produced from xanthine by xanthine oxidase. This possibility would also be consistent with the inability of catalase to show significant inhibitory effects in lungs injected with xanthine and xanthine oxidase. Since higher doses of SOD (5 mg) showed only a small increase in inhibition of lung injury and bovine serum albumin ( $5 \mathrm{mg}$, experiment $\mathrm{C}$ ), failed to alter the effects of xanthine-xanthine oxidase, this suggests that the effects of SOD are specific and do not represent nonspecific inhibition due to the presence of protein.

The inability of xanthine oxidase to produce lung injury in the absence of xanthine (Table I, experiment A) suggests that the effects of the enzyme in lung are specific to the substrate (xanthine) and not likely due to the presence of contaminating materials such as proteases. Further evidence supporting this is found in experiment $B$ in which the xanthine oxidase was pretreated with PMSF to inactivate protease contaminants. This did not interfere with the lung-damaging activities of the xanthine oxidase when compared with the nonPMSF-treated preparation which was used in experiment $\mathrm{C}$.

Acute pulmonary injury produced by glucose oxidase-lactoperoxidase. A series of experiments was carried out, as described in Table II, in which various combinations of enzymes were used to generate a variety of oxygen metabolites. As seen in experiment $A$, the intrapulmonary instillation of saline caused the usual, minimal change of permeability within the lung. When a limited dose ( $28 \mathrm{U})$ of glucose oxidase was instilled into rat lungs, the permeability changes relative to the effects of saline increased by a factor of 2 , to a value of 0.35 . However, the addition to the glucose oxidase preparation of $1.7 \mathrm{U}$ of lactoperoxidase markedly accentuated the pulmonary damage, causing a nearly threefold increase (0.93) in the degree of lung injury when compared with injury produced by glucose oxidase dose (0.35). That the lactoperoxidase per se was not the cause of this marked accentuation of tissue injury was shown by the inability of lactoperoxidase, 
TABLE I

Pulmonary Damage Induced by Products of Xanthine Oxidase

\begin{tabular}{|c|c|c|c|c|c|}
\hline \multirow[b]{2}{*}{ Experiment } & \multirow[b]{2}{*}{ Material injected into lungs } & \multirow{2}{*}{$\begin{array}{l}\text { Number } \\
\text { of animals }\end{array}$} & \multicolumn{2}{|c|}{ Lung damage (permeability value)* } & \multirow{2}{*}{$\begin{array}{c}\text { Inhibition } \\
\text { of lung } \\
\text { damage }\end{array}$} \\
\hline & & & Individual values & Mean \pm SEM & \\
\hline \multirow[t]{4}{*}{ A } & Xanthine + xanthine oxidase & 7 & $\begin{array}{l}1.51 ; 2.22 ; 1.20 ; 1.54 \\
1.48 ; 1.76 ; 1.43\end{array}$ & $1.59 \pm 0.12$ & \\
\hline & Xanthine & 3 & $0.25 ; 0.23 ; 0.25$ & $0.24 \pm 0.01$ & \\
\hline & Xanthine oxidase & 3 & $0.29 ; 0.21 ; 0.25$ & $0.25 \pm 0.02$ & \\
\hline & Saline & 4 & $0.26 ; 0.24 ; 0.24 ; 0.27$ & $0.25 \pm 0.01$ & \\
\hline \multirow[t]{5}{*}{ B } & Xanthine + xanthine oxidase & 3 & $3.37 ; 3.42 ; 3.22$ & $3.34 \pm 0.06$ & \\
\hline & Xanthine + xanthine oxidase & & & & \\
\hline & + SOD $\$(2.5 \mathrm{mg})$ & 3 & $1.67 ; 2.64 ; 1.83$ & $2.04 \pm 0.30$ & 42 \\
\hline & Xanthine + xanthine oxidase & & & & \\
\hline & + SOD $(5 \mathrm{mg})$ & 3 & $1.28 ; 1.34 ; 1.20$ & $1.27 \pm 0.03$ & 67 \\
\hline \multirow[t]{3}{*}{$\mathrm{C}$} & Xanthine + xanthine oxidase & 3 & $2.26 ; 1.75 ; 1.43$ & $1.81 \pm 0.24$ & \\
\hline & Xanthine + xanthine oxidase & & & & \\
\hline & $+\mathrm{SOD}(2.5 \mathrm{mg})$ & 3 & $0.88 ; 0.90 ; 0.85$ & $0.87 \pm 0.01$ & 60 \\
\hline \multirow[t]{6}{*}{$\mathrm{D}$} & Xanthine + xanthine oxidase & 2 & $1.54 ; 1.49$ & $1.51 \pm 0.02$ & \\
\hline & Xanthine + xanthine oxidase & & & & \\
\hline & + SOD $(2.5 \mathrm{mg})$ & 2 & $0.91 ; 0.84$ & $0.87 \pm 0.02$ & 54 \\
\hline & Xanthine + xanthine oxidase & & & & \\
\hline & + catalase & 2 & $1.33 ; 1.48$ & $1.41 \pm 0.05$ & 8 \\
\hline & Saline & 2 & $0.25 ; 0.37$ & $0.31 \pm 0.04$ & \\
\hline \multirow[t]{8}{*}{$\mathrm{E}$} & Xanthine + xanthine oxidase & 2 & $0.58 ; 0.57$ & $0.58 \pm 0.004$ & \\
\hline & Xanthine + xanthine oxidase & & & & \\
\hline & $+\operatorname{SOD}(2.5 \mathrm{mg})$ & 3 & $0.32 ; 0.46 ; 0.38$ & $0.39 \pm 0.03$ & 61 \\
\hline & Xanthine + xanthine oxidase & & & & \\
\hline & + catalase & 2 & $0.70 ; 0.57$ & $0.64 \pm 0.05$ & 0 \\
\hline & Xanthine + xanthine oxidase & & & & \\
\hline & $+\mathrm{SOD}(2.5 \mathrm{mg})+$ catalase & 3 & $0.43 ; 0.38 ; 0.34$ & $0.38 \pm 0.02$ & 65 \\
\hline & Saline & 3 & $0.23 ; 0.32 ; 0.26$ & $0.27 \pm 0.02$ & \\
\hline \multirow[t]{3}{*}{$\mathbf{F}$} & Xanthine + xanthine oxidase & 2 & $0.82 ; 0.83$ & $0.82 \pm 0.005$ & \\
\hline & $\begin{array}{c}\text { Xanthine + xanthine oxidase } \\
+ \text { bovine serum albumin }\end{array}$ & & & & \\
\hline & (5 mg) & 2 & $0.88 ; 0.91$ & $0.89 \pm 0.015$ & 0 \\
\hline
\end{tabular}

\footnotetext{
* Three negative controls in each experiment received saline into the airways. The mean values of these animals were used in each experiment to establish the ratios.

$\$$ When SOD was used, $2.5 \mathrm{mg}$ was added to the mixture in a final vol of $200 \mu \mathrm{l}$; for catalase, $5.0 \mathrm{mg}$ was employed. In experiment B, the xanthine oxidase was pretreated with PMSF to inactivate contaminating serine esterase-type protease(s) present. In experiment $C$, the companion preparation (non-PMSF treated) of xanthine oxidase was employed. (See Methods for details.) The dose of xanthine oxidase employed in the experiments was: A, $0.6 \mathrm{U}$; $\mathrm{B}, \mathrm{C}, \mathrm{D}, 2.5 \mathrm{U}$; and E, $0.2 \mathrm{U}$.
}

given alone, to cause significant lung injury. An additional control (Table II, experiment A) emphasizing the synergistic effects of glucose oxidase and lactoperoxidase was demonstrated by the substitution of horseradish peroxidase for lactoperoxidase, since the former is a nonhalide-dependent peroxidase (21). Horseradish peroxidase was unable to cause an increment in the amount of tissue injury produced by glucose oxidase (Table II, experiment A).

If, in the absence of lactoperoxidase, the amount of glucose oxidase were increased 2.5 -fold (to $70 \mathrm{U}$ ), then marked lung injury was seen, being nearly sixfold (value of 1.36) above the saline control values. However, even with this high level of injury, intensification of the injury occurred when a small amount of lactoperoxidase was added to the glucose oxidase mixture (Table II, experiment B, value of 1.89). The ability of glucose oxidase to cause lung injury was abolished if the enzyme preparation was first heat-inactivated (Table II, experiment B), resulting in an average lung 
TABLE II

Pulmonary Damage Produced by Generators of Oxygen Metabolites

\begin{tabular}{|c|c|c|c|c|c|}
\hline \multirow[b]{2}{*}{ Experiment } & \multirow[b]{2}{*}{ Material injected into lungs* } & \multirow[b]{2}{*}{$n !$} & \multicolumn{2}{|c|}{ Lung damage§ } & \multirow[b]{2}{*}{$P$ value } \\
\hline & & & Individual animals & Mean \pm SEM & \\
\hline \multirow[t]{7}{*}{ A } & Saline + glucose & 4 & $0.14,0.16,0.20,0.21$ & $0.18 \pm 0.02$ & \\
\hline & Glucose oxidase $(28 \mathrm{U})+$ glucose & 3 & $0.41,0.35,0.28$ & $0.35 \pm 0.04$ & $<0.01$ \\
\hline & Glucose oxidase $(28 \mathrm{U})+$ glucose & & & & \\
\hline & + lactoperoxidase (1.7 U) & 3 & $0.91,1.04,0.84$ & $0.93 \pm 0.06$ & $<0.001$ \\
\hline & Glucose oxidase $(28 \mathrm{U})+$ glucose & & & & \\
\hline & + horseradish peroxidase (5 U) & 3 & $0.30,0.37,0.34$ & $0.34 \pm 0.02$ & $<0.005$ \\
\hline & Lactoperoxidase $(1.7 \mathrm{U})+$ glucose & 2 & $0.15,0.26$ & $0.21 \pm 0.05$ & NS \\
\hline \multirow[t]{4}{*}{ B } & Glucose oxidase $(70 \mathrm{U})+$ glucose & 3 & $0.78,1.86,1.43$ & $1.36 \pm 0.31$ & $<0.001$ \\
\hline & Glucose oxidase $(70 \mathrm{U})+$ glucose & & & & \\
\hline & + lactoperoxidase (1.7 U) & 3 & $2.02,1.96,1.68$ & $1.89 \pm 0.10$ & $<0.001$ \\
\hline & $\begin{array}{l}\text { Heat-inactivated glucose oxidase } \\
(70 \mathrm{U})+\text { glucose }\end{array}$ & 2 & $0.21,0.31$ & $0.26 \pm 0.05$ & NS \\
\hline \multirow[t]{4}{*}{$\mathrm{C}$} & Galactose oxidase $(20 \mathrm{U})+$ glucose & 4 & $0.20,0.31,0.28,0.19$ & $0.25 \pm 0.03$ & NS \\
\hline & Galactose oxidase $(20 \mathrm{U})+$ galactose & 3 & $0.20,0.31,0.27$ & $0.26 \pm 0.03$ & NS \\
\hline & Galactose oxidase $(20 \mathrm{U})+$ galactose & & & & \\
\hline & + lactoperoxidase (1.7 U) & 3 & $0.87,0.57,0.47$ & $0.64 \pm 0.12$ & $<0.01$ \\
\hline \multirow[t]{5}{*}{$\mathrm{D}$} & Glucose oxidase $(35 \mathrm{U})+$ glucose & & & & \\
\hline & + myeloperoxidase $(5 \mathrm{U})$ & 3 & $1.13,1.86,1.54$ & $1.51 \pm 0.21$ & $<0.01$ \\
\hline & Glucose oxidase $(35 \mathrm{U})+$ glucose & 3 & $0.55,0.42,0.49$ & $0.49 \pm 0.03$ & $<0.05$ \\
\hline & Myeloperoxidase $(5 \mathrm{U})+$ glucose & 2 & $0.45,0.42$ & $0.43 \pm 0.02$ & $<0.01$ \\
\hline & Saline + glucose & 3 & $0.38,0.28,0.34$ & $0.33 \pm 0.03$ & \\
\hline
\end{tabular}

* Quantities of glucose oxidase, galactose oxidase, and lactoperoxidase represent stock solution activities. See Methods for enzymatic activity of glucose oxidase at $\mathrm{pH} 7.4,37^{\circ} \mathrm{C}$.

\$ Number of animals.

$\S$ Permeability values (Methods).

"All $P$ values were derived from comparing permeability changes in saline-injected lungs with those in enzymeinjected animals.

permeability value of 0.26 , which was very close to the values produced by saline alone (Table II, experiments A and D).

In additional experiments, the enzyme preparation, galactose oxidase, was used in limiting amounts since its substrate would not be available in the lung tissue. In small amounts (20 U), galactose oxidase plus glucose or galactose oxidase plus galactose caused little if any evidence of lung injury when instilled into rat lung (Table II, experiment $\mathrm{C}$, mean values of 0.25 and 0.26 ). The reference saline controls for this experiment are contained in experiment $D$, with a value of 0.33 . However, as was the case with glucose oxidase, the addition of lactoperoxidase greatly accentuated the degree of tissue injury, causing a 2.5-fold increase (to a value of 0.64 ) in the changes in lung permeability.

Finally, in experiment D (Table II), lung damage produced by $35 \mathrm{U}$ of glucose oxidase (with glucose) was greatly augmented by the presence of peripheral human leukocytic myeloperoxidase. The injury induced by instillation of either glucose oxidase alone (Table II, experiment D, value of 0.49 ) or myeloperoxi- dase alone (value of 0.43 ) was only slightly greater than the values obtained in the negative (saline-instilled) lungs (Table II, experiment D, value of 0.33 ), whereas the mixture of the two enzymes resulted in greatly intensified lung injury, with a 2.5 -fold increase in lung permeability (Table II, experiment D, value of 1.51 ). These data indicate that, like lactoperoxidase, myeloperoxidase has the ability to intensify glucose oxidaseinduced injury of lung.

The data in Table II suggest that lung injury can be produced if sufficient amounts of $\mathrm{H}_{2} \mathrm{O}_{2}$ are produced within the lung. However, the most intense injury appears to occur, not with production of $\mathrm{H}_{2} \mathrm{O}_{2}$ alone, but with its metabolic, peroxidative conversion (by lactoperoxidase or myeloperoxidase), possibly involving products such as $\mathrm{HOCl}$. Based on the inability of horseradish peroxidase to accentuate the injury produced by glucose oxidase, it seems likely that the end product is halide-dependent, as is well shown for injury of bacteria and cells produced by glucose oxidase and myeloperoxidase or lactoperoxidase $(6,22)$.

Inhibition by catalase of glucose oxidase and lacto- 
TABLE III

Inhibition by Catalase of Lung Injury Produced by Glucose Oxidase and Lactoperoxidase

\begin{tabular}{|c|c|c|c|c|c|}
\hline \multirow{2}{*}{\multicolumn{2}{|c|}{ Material instilled into lungs* }} & \multirow{2}{*}{$\begin{array}{l}\text { Number } \\
\text { animals }\end{array}$} & \multicolumn{2}{|l|}{ Lung damage } & \multirow{2}{*}{$\begin{array}{l}\text { Inhibition of } \\
\text { lung damage }\end{array}$} \\
\hline & & & Individual values & Mean \pm SEM & \\
\hline & & & & & $\%$ \\
\hline \multirow[t]{6}{*}{ A } & Glucose oxidase + lactoperoxidase & 6 & $2.72,2.54,2.75,3.25,1.94,2.44$ & $2.61 \pm 0.18$ & - \\
\hline & Glucose oxidase + lactoperoxidase & & & & \\
\hline & + catalase $(10 \mathrm{mg})$ & 5 & $0.27,0.50,0.34,0.31,0.50$ & $0.38 \pm 0.05$ & 96 \\
\hline & Glucose oxidase + lactoperoxidase & & & & \\
\hline & + SOD (6 mg) & 3 & $2.15,2.00,2.94$ & $2.36 \pm 0.29$ & 10 \\
\hline & Saline & 4 & $0.28,0.34,0.29$ & $0.30 \pm 0.02$ & - \\
\hline \multirow[t]{8}{*}{ B } & Glucose oxidase + lactoperoxidase & 3 & $1.57,2.53,1.98$ & $2.03 \pm 0.28$ & - \\
\hline & + catalase $(10 \mathrm{mg})$ & 5 & $0.27,0.50,0.31,0.34,0.50$ & $0.38 \pm 0.05$ & 95 \\
\hline & Glucose oxidase + lactoperoxidase & & & & \\
\hline & + catalase $(5 \mathrm{mg})$ & 3 & $0.44,0.33,0.35$ & $0.37 \pm 0.03$ & 96 \\
\hline & Glucose oxidase + lactoperoxidase & & & & \\
\hline & + catalase $(1 \mathrm{mg})$ & 3 & $0.86,0.35,1.08$ & $0.76 \pm 0.22$ & 73 \\
\hline & Glucose oxidase + lactoperoxidase & & & & \\
\hline & + catalase $(0.5 \mathrm{mg})$ & 3 & $1.02,0.64,1.07$ & $0.91 \pm 0.14$ & 65 \\
\hline \multirow[t]{5}{*}{ C } & Glucose oxidase + lactoperoxidase & 3 & $0.74,0.62,1.46$ & $0.94 \pm 0.26$ & - \\
\hline & Glucose oxidase + lactoperoxidase & & & & \\
\hline & + active catalase $(5 \mathrm{mg})$ & 4 & $0.31,0.26,0.42,0.35$ & $0.34 \pm 0.03$ & 94 \\
\hline & Glucose oxidase + lactoperoxidase & & & & \\
\hline & + inactive catalase $(5 \mathrm{mg}) \ddagger$ & 4 & $0.85,0.59,1.32,1.04$ & $0.95 \pm 0.15$ & 0 \\
\hline
\end{tabular}

* All animals received $1.0 \mathrm{mg}$ glucose instilled into the airways. When used, the amounts (unless otherwise specified) of the other reagents were: glucose oxidase, $30 \mathrm{U}$; myeloperoxidase, $5 \mathrm{U}$; lactoperoxidase, $5 \mathrm{U}$; catalase, $10 \mathrm{mg}$; SOD, $6 \mathrm{mg}$. Glucose oxidase activity represent stock solution values.

$\ddagger$ Inactive catalase was produced by reduction alkylation of catalase. This resulted in $<1 \%$ residual enzyme activity. See Methods for details.

peroxidase-induced lung injury. Requirements for optimal production of lung injury by enzymes that generate oxygen metabolic products has been demonstrated in the data presented in Tables I and II. Further definition of the presumed nature of the agents responsible for lung injury was obtained by the use of inhibitors, as described in Table III. In this experiment, lung injury produced by the instillation of glucose oxidase and lactoperoxidase could be blocked by the addition of catalase but not by SOD. The presence of $10 \mathrm{mg}$ catalase blocked $96 \%(P<0.001)$ of the lung injury, whereas only $10 \%$ inhibition was effected by SOD. A dose-response for catalase-induced inhibition of lung injury was carried out over a dose range of 0.5-10.0 $\mathrm{mg}$ of catalase. As the data in Table III, experiment B indicate, the inhibition was directly related to the amount of catalase employed, with the half-infective dose of the inhibitor being close to $0.5 \mathrm{mg}$ (which gave a mean inhibition value of $65 \%(P<0.02)$.

In experiment $C$ the question was addressed as to whether catalase-induced inhibition of lung injury produced by the instillation of glucose + glucose oxidase
+ lactoperoxidase was specific for the enzymatic activity of catalase or might be due to nonspecific inhibition due to the presence of protein. Accordingly, lung injury was compared in animals receiving active catalase (which was mixed with the enzyme reagents) with those receiving chemically inactivated catalase. As the data in Table III (experiment $C$ ) show, active catalase afforded $94 \%$ inhibition of lung injury ( $P$ $<0.01$ ) whereas no protection against the lung injury was found with the chemically inactivated catalase. The results indicate that the protective effects of catalase are related to its enzymatic activity.

The data described in Table III are consistent with the interpretation that the intense, acute lung injury produced by glucose oxidase and lactoperoxidase is related to metabolic products of $\mathrm{H}_{2} \mathrm{O}_{2}$ and, as would be expected, does not involve $\mathrm{O}_{2}^{-}$to any appreciable degree.

Neutrophil-independent lung injury produced by high doses of glucose oxidase. Whereas the data described above suggest that maximal lung injury occurs with the combination of glucose oxidase and lacto- 
peroxidase, higher doses of glucose oxidase per se can inflict severe lung injury (Table II). To determine if the latter findings were due to recruitment into the lung parenchyma of leukocytes with release of myeloperoxidase, a series of rats was rendered neutropenic with specific antibody (15). The amount of glucose oxidase instilled into the airways was $35 \mathrm{U}$. The results of these experiments are shown in Table IV. The intrapulmonary instillation of glucose oxidase into neutrophilintact and neutrophil-depleted rats caused lung injury values two- and threefold above those of the negative controls (Table IV, mean values of 0.51 and 0.84 , for nonneutropenic and neutropenic rats, respectively). Quite unexpectedly, not only did the neutropenic animals fail to show evidence of suppression of lung injury, these animals, when compared with neutrophilintact rats, actually showed a 1.6-fold enhancement ( $P$ $<0.001$ ) of the acute pulmonary injury produced by glucose oxidase (Table IV, animals 1-8). These data suggest that $\mathrm{H}_{2} \mathrm{O}_{2}$ or subsequent metabolites may, if present in adequate amounts, directly injure the lung and that the absence of available neutrophils intensifies the outcome. It is possible that the antineutrophil antibody caused sequestration of neutrophils in the pulmonary capillaries, resulting in accentuation of the injury produced by glucose oxidase and lactoperoxidase.
However, in earlier studies we have demonstrated that the same conditions of neutrophil depletion do not, per se, result in evidence of lung injury (19). Furthermore, by morphological analysis, no evidence of sequestered neutrophils within the pulmonary vasculature was noted. Finally, the antibody to neutrophils was injected $18 \mathrm{~h}$ before these experiments were undertaken. At this point, few if any circulating neutrophils are found and it is assumed that inhibition of output of leukocytes from the bone marrow is occurring. Thus, if sequestered neutrophils contribute to the injury described in this paper, their role is not obvious.

Morphological changes produced by oxygen metabolites. Intrapulmonary instillation of the various enzyme-substrate combinations described above was routinely monitored by light microscopy of fixed and stained sections of lung. The results are described in Fig. 1. At $4 \mathrm{~h}$, the instillation of $2.5 \mathrm{U}$ xanthine oxidase and xanthine was associated with acute congestion of pulmonary capillaries, traces of intraalveolar hemorrhage as revealed by occasional erythrocytes, and minimal perivascular edema (Fig. 1A). At $7 \mathrm{~d}$ and $14 \mathrm{~d}$, the morphology of the lungs was normal. $4 \mathrm{~h}$ after instillation of $2.8 \mathrm{U}$ of glucose oxidase, $1.7 \mathrm{U}$ lactoperoxidase and $1.0 \mathrm{mg}$ glucose, the morphological changes included a smudging of alveolar walls (es-

TABLE IV

Effect of Neutrophil Depletion on Glucose Oxidase-Induced Lung Injury*

\begin{tabular}{clcl}
\hline $\begin{array}{c}\text { Animal } \\
\text { number }\end{array}$ & \multicolumn{1}{c}{ Material injected into lung } & $\begin{array}{c}\text { Neutrophils/ } \\
\mathrm{mm}^{3} \text { blood }\end{array}$ & Lung damage \\
\hline 1 & Glucose oxidase & 380 & 0.82 \\
2 & Glucose oxidase & 720 & 0.83 \\
3 & Glucose oxidase & 580 & 0.88 \\
4 & Glucose oxidase & 287 & 0.64 \\
5 & Glucose oxidase & $<200$ & 0.91 \\
6 & Glucose oxidase & $<500$ & 1.02 \\
7 & Glucose oxidase & $<500$ & 0.71 \\
8 & Glucose oxidase & 1,500 & 0.89 \\
Mean \pm SEM & & & $0.84 \pm 0.04$ \\
9 & Glucose oxidase & 4,250 & 0.46 \\
10 & Glucose oxidase & 4,500 & 0.48 \\
11 & Glucose oxidase & 4,000 & 0.54 \\
12 & Glucose oxidase & 4,500 & 0.58 \\
13 & Glucose oxidase & 4,200 & 0.44 \\
14 & Glucose oxidase & 4,000 & 0.58 \\
Mean \pm SEM & & & $0.51 \pm 0.03$ \\
15 & Glucose oxidase, heat inactivated & 4,540 & 0.29 \\
16 & Glucose oxidase, heat inactivated & 4,800 & 0.28 \\
17 & Glucose oxidase, heat inactivated & 4,200 & 0.21 \\
18 & Glucose oxidase, heat inactivated & 4,200 & 0.31 \\
Mean \pm SEM & & & $0.27 \pm 0.02$ \\
\hline
\end{tabular}

* $35 \mathrm{U}$ glucose oxidase was instilled into the airways. Glucose oxidase activity represents stock solution values. 

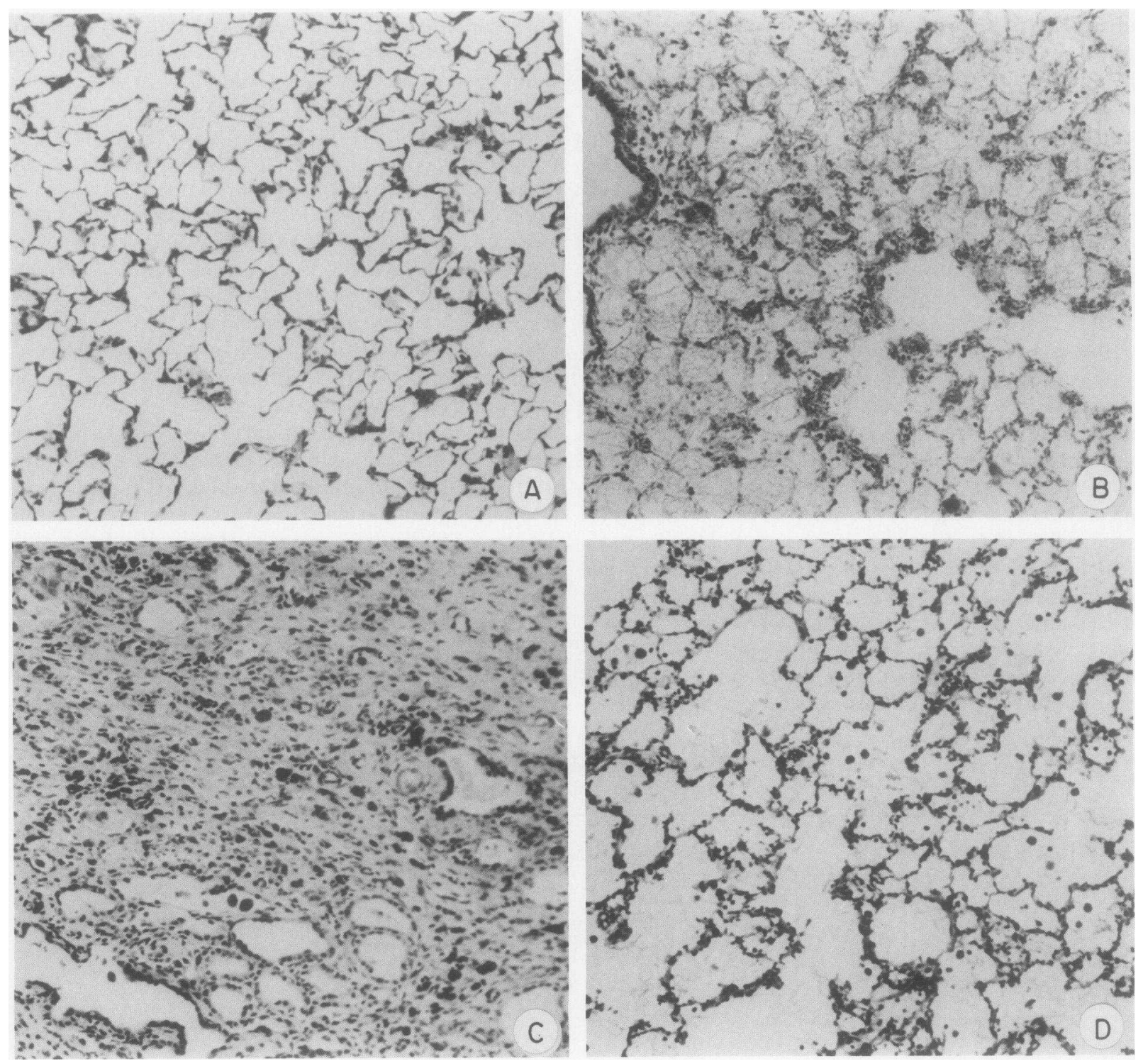

FIGURE 1 (A) Section of lung from rat receiving an intrapulmonary instillation $4 \mathrm{~h}$ earlier of xanthine and xanthine oxidase $(2.5 \mathrm{U})$. Morphological changes are minor but include acute congestion and minimal perivascular edema. (B) Section of lung from animal receiving an intrapulmonary injection of glucose $(1 \mathrm{mg})$, glucose oxidase $(28 \mathrm{U})$, and lactoperoxidase (1.7 $\mathrm{U}) 4 \mathrm{~h}$ earlier. There is smudging of alveolar walls with neutrophils, minimal hemorrhage, and pronounced intraalveolar deposits of fibrin. (C) Section of lung from animal treated similar to that in B, but $14 \mathrm{~d}$ later. There is collapse of lung tissue, loss of alveolar outlines, and extensive interstitial fibrosis. (D) Section from lung of rat treated $4 \mathrm{~h}$ earlier with glucose $(1 \mathrm{mg})$, and glucose oxidase $(70 \mathrm{U})$, but without lactoperoxidase. The lung changes include neutrophils in alveolar spaces and in the interstitium, and early intraalveolar hemorrhage and deposits of fibrin. (Hematoxylin and eosin, $\times 40$.)

pecially in the area of the respiratory bronchioles) associated with the presence of neutrophils, early intraalveolar hemorrhage, and rather extensive intraalveolar deposits of fibrin (Fig. 1B). $14 \mathrm{~d}$ later these lungs showed evidence of collapse with extensive interstitial fibrosis, obliteration of alveolar spaces, and scattered macrophages filled with hemosiderin pigment (Fig. 1C). When the dose of glucose oxidase was increased more than twofold $(70 \mathrm{U})$ in the absence of lactoperoxidase (Fig. 1D), there were acute inflammatory changes at $4 \mathrm{~h}$ which were morphologically similar to those seen at the lower dose of glucose oxidase plus lacto- 
peroxidase (Fig. 1B). However, in the absence of lactoperoxidase, there was resolution of the inflammatory reaction without progression to fibrosis. In a companion group of animals treated with the same combination of enzymes and substrate but also receiving $5.0 \mathrm{mg}$ catalase, the lung morphology at $4 \mathrm{~h}$ and at $14 \mathrm{~d}$ was essentially normal (data not shown).

\section{DISCUSSION}

The ability of $\mathrm{O}_{2}^{-}$, which has been generated by xanthine-xanthine oxidase, to damage erythrocytes has been demonstrated by others $(23,24)$. In more complex systems in which the role of oxygen metabolites in leukocyte-mediated injury of erythrocytes, endothelial cells, and tumor cells have been probed, evidence has been obtained that $\mathrm{O}_{2}^{-}$and $\mathrm{H}_{2} \mathrm{O}_{2}$, or myeloperoxidaseinduced metabolites of $\mathrm{H}_{2} \mathrm{O}_{2}$ (such as ${ }^{1} \mathrm{O}_{2}$ and $\mathrm{HOCl}$ ) play a direct role in target cell injury $(5,9,10,25,26)$. In vivo, the evidence that these or other highly reactive metabolites play a role in injury has been largely of an indirect nature. For instance, in deoxyrubicininduced myocardial toxicity, a fall in the levels of glutathione peroxidase has been taken to reflect impaired defenses against formation of $\mathrm{H}_{2} \mathrm{O}_{2}$ (3). In rats given paraquat or diquat, a selenium-dependent factor other than glutathione peroxidase has been suggested as being involved in removal of $\mathrm{O}_{2}^{-}(4)$. Finally, the ability of SOD to diminish the early phases of acute vascular injury produced by immune complexes in rats has suggested that $\mathrm{O}_{2}^{-}$may play a direct or an indirect role in the early phase of the reactions that are triggered by immune complexes and lead to vascular damage $(13,14)$.

The studies presented in this paper have the advantage that more direct conclusions can be reached regarding the susceptibility of the lung to damage produced by enzymes that generate an array of unstable oxygen products. Our data suggest that direct $\left(\mathrm{O}_{2}^{-}\right)$ products of xanthine oxidase will cause acute lung damage, that $\mathrm{H}_{2} \mathrm{O}_{2}$ may directly be lung-damaging (using high doses of glucose oxidase), and that products of glucose oxidase and lactoperoxidase $\left({ }^{1} \mathrm{O}_{2}\right.$ and perhaps halide-dependent products) are particularly lungdamaging. It is obviously extremely difficult to be precise about which of these products are more important. The inability of SOD to protect the lung from injury produced by glucose oxidase and lactoperoxidase suggests that the critical products produced by this combination of enzymes do not involve $\mathrm{O}_{2}^{-}$. The ability of catalase to protect the lung from the damage suggests that $\mathrm{H}_{2} \mathrm{O}_{2}$ or its metabolic products are central to the injury. Since horseradish peroxidase cannot potentiate the lung damage produced by glucose oxidase, the well-known halide-dependent pathway described for cell injury produced by glucose oxidase and lactoperoxidase/myeloperoxidase would seem to be a likely possibility, although the halide preferred by lactoperoxidase is iodide, not chloride. In experiments employing large doses $(70 \mathrm{U})$ of glucose oxidase in the absence of lactoperoxidase, lung damage may be the direct result of the generation of $\mathrm{H}_{2} \mathrm{O}_{2}$, since the availability of neutrophils (and their content of myeloperoxidase) is not involved in the injury resulting from the instillation of this product. Although it could be argued that myeloperoxidase from alveolar macrophages (or other lung cells) could be involved in a metabolic conversion of $\mathrm{H}_{2} \mathrm{O}_{2}$, the finding that neutrophil depletion actually enhances the degree of lung injury could be interpreted to suggest that when glucose oxidase alone is instilled into the lung in sufficient quantities, the resulting injury is due to $\mathrm{H}_{2} \mathrm{O}_{2}$ and not to derivative products. Again, there is an in vitro parallel with this observation. Neutrophils activated with phorbol myristate acetate will cytolytically alter erythrocytes in a manner that is dependent on $\mathrm{H}_{2} \mathrm{O}_{2}$ (and $\mathrm{O}_{2}^{-}$) but not upon myeloperoxidase-mediated pathways (25). This observation suggests a possible in vivo role of the Haber-Weiss reaction (or the enhanced iron-catalyzed reaction) and its metabolic products:

$$
\begin{aligned}
& \mathrm{O}_{2}^{-}+\mathrm{Fe}^{3+} \rightarrow \mathrm{O}_{2}+\mathrm{Fe}^{2+} \\
& \mathrm{Fe}^{2+}+\mathrm{H}_{2} \mathrm{O}_{2} \rightarrow \mathrm{Fe}^{3+}+\mathrm{OH}^{-}+\mathrm{OH} \\
& \hline \mathrm{O}_{2}^{-}+\mathrm{H}_{2} \mathrm{O}_{2} \rightarrow \mathrm{O}_{2}+\mathrm{OH}^{-}+\mathrm{OH} .
\end{aligned}
$$

The observation that catalase neither inhibited the lung injury induced with xanthine-xanthine oxidase nor enhanced the inhibition of SOD suggests that under the conditions described here products of the reaction of $\mathrm{O}_{2}^{-}$with $\mathrm{H}_{2} \mathrm{O}_{2}$ do not play a significant role in the induction of lung injury. However, these experiments are limited by the solubility of xanthine in aqueous solution, restricting the quantity of $\mathrm{O}_{2}^{-}$generated and thereby influencing the potential formation of $\mathrm{H}_{2} \mathrm{O}_{2}$ and other metabolic products. Therefore, the observations presented here do not exclude the possibility that products of the Haber-Weiss reaction play a role on the in vivo induction of neutrophil-mediated injury.

The data presented in the paper, together with the other observations cited above, suggest the likelihood that in leukocyte-dependent tissue injury, such as that induced by immune complexes, the key products may include a variety of oxygen derivatives, involving $\mathrm{O}_{2}^{-}$, $\mathrm{H}_{2} \mathrm{O}_{2}$, and myeloperoxidase-induced products of $\mathrm{H}_{2} \mathrm{O}_{2}$, similar to the bactericidal activity and the killing of murine tumor cells as originally described by Klebanoff and his colleagues $(5,22)$. Although we do not have direct evidence that halide is involved in the reactions described in Table II, the inability of horseradish peroxidase to potentiate the damage caused by 
glucose oxidase implicates the direct role of myeloperoxidase (lactoperoxidase) $-\mathrm{H}_{2} \mathrm{O}_{2}$-halide system.

With regard to the manner by which neutrophils cause tissue injury in immune complex-triggered reactions, the prevailing concepts include protease-inflicted injury due to hydrolysis of susceptible structural proteins (reviewed, 27), the generation of secondary inflammatory mediators that intensify the reaction (28), and injury due to the production of toxic oxygen metabolites. Confirmation of the direct role of leukocytic proteases has not been achieved. In fact, the evidence is to the contrary. Firstly, in mice the intensity of vascular damage produced by immune complexes is as intense in animals whose leukocytes have $<5 \%$ neutral protease content as compared with injury produced in animals whose leukocytes have a full complement of leukocytic neutral proteases (29). Secondly, we have been unable to block the immune complex-induced injury of lung and of dermal blood vessels with antiproteases that block neutrophil proteases, even though protection of this injury can be achieved with SOD (14) and with catalase (unpublished observations). It is interesting to note that the ability of SOD to block the reaction occurs only over the first $2 \mathrm{~h}$, whereas catalase produces a sustained protective effect. These results could be interpreted to indicate that the neutrophil-related injury of tissue involves the early role of $\mathrm{O}_{2}^{-}$and that the injury is propagated and intensified by $\mathrm{H}_{2} \mathrm{O}_{2}$ and/or its metabolic products. Thus, injury could be occurring through the direct action of $\mathrm{O}_{2}^{-}$, followed by its dismutation to $\mathrm{H}_{2} \mathrm{O}_{2}$, which is metabolized by neutrophils to $\mathrm{HOCl}$, a proven injurious product. There is, of course, no in vivo evidence that the toxic derivative of $\mathrm{H}_{2} \mathrm{O}_{2}$ is halide-dependent. Peroxidation reactions may represent the sole mechanism of injury, although in vitro studies clearly demonstrate a halide-dependent nature of cell injury that is produced by activated neutrophils and is related to toxic oxygen metabolites $(5,6)$.

There is ample evidence that neutrophils activated by chemotactic peptides (which are known to be generated in immune complex triggered reactions) generate prodigious quantities of oxygen metabolites. For instance, $5 \times 10^{6}$ neutrophils activated in vitro by a chemotactic peptide produce $7.9 \mathrm{nmol} \mathrm{O}_{2}^{-} / 5 \mathrm{~min}$ and $9.0 \mathrm{nmol} \mathrm{H}_{2} \mathrm{O}_{2} / 5 \mathrm{~min}$. Under the same conditions, lysozyme (a sensitive marker for lysosomal protease secretion) is not released (30). On the basis of our recent studies measuring the accumulation of neutrophils in lungs injected with chemotactic peptides, as a model of neutrophil dependent lung injury, it can be calculated that over a 4 -h period, $\sim 5 \times 10^{6}{ }^{111}$ In-labeled neutrophils accumulate in the lung (31). Since the indium-labeled neutrophils represent $\sim 20 \%$ of the total neutrophil count in each animal, the actual number of neutrophils present in the lung more closely approaches $2.5 \times 10^{7}$ cells. If these leukocytes were activated by the chemotactic peptide in a manner similar to the in vitro studies, the potential would exist for the generation within the lung over a 4 -h period of 39.5 nmol $\mathrm{O}_{2}^{-}$and $45 \mathrm{nmol}_{2} \mathrm{O}_{2}$. However, if these neutrophils are activated by phagocytosis of particulate matter or immune complexes, the estimated total amount of $\mathrm{O}_{2}^{-}$and $\mathrm{H}_{2} \mathrm{O}_{2}$ generated would potentially be 500 (32) and $100 \mathrm{nmol}$ (33), respectively. Since the quantity of each reactive metabolite generated in vitro by neutrophils is dependent on species and stimulus, these calculations serve only as gross approximations of the actual amounts of $\mathrm{O}_{2}^{-}$and $\mathrm{H}_{2} \mathrm{O}_{2}$ generated in vivo and emphasize the difficulty of assessing in vivo the precise quantity of reactive oxygen-derived metabolites generated in an acute inflammatory reaction. Nevertheless, these estimates do emphasize the considerable potential for the generation by neutrophils of a series of oxygen metabolites that have the proven capacity to injure cells.

Finally, the progression to interstitial pulmonary fibrosis of lungs from animals injured by instillation of glucose oxidase and lactoperoxidase and the lack of evolution in catalase protected rats suggest that oxygen metabolites may directly or indirectly represent an important factor in the pathogenesis of interstitial pulmonary fibrosis. The evidence from patients with idiopathic pulmonary fibrosis incriminating the role of immune complexes and neutrophils (34) provides an intriguing possible link with the studies presented in this paper. Obviously, much work remains before the linkage of pulmonary fibrotic changes and neutrophilgenerated oxygen metabolites can be confirmed.

\section{ACKNOWLEDGMENTS}

This work was supported by National Institutes of Health grants AI-09651, HL-23192, HL-07202, HL-00598, and a grant from the Connecticut Lung Association.

\section{REFERENCES}

1. Saltzman, H. A., and I. Fridovich. 1973. Oxygen toxicity. Introduction to a protective enzyme: superoxide dismutase. Circulation. 48: 921-923.

2. Rister, M., and R. L. Baehner. 1976. The alteration of superoxide dismutase, catalase, glutathione peroxidase, $\mathrm{NAD}(\mathrm{P}) \mathrm{H}$, cytochrome $\mathrm{C}$ reductase in guinea pig polymorphonuclear leukocytes and alveolar macrophages during hyperoxia. J. Clin. Invest. 58: 1174-1184.

3. Doroshow, J. H., G. Y. Locker, and C. E. Myers. 1980. Enzymatic defenses of the mouse heart against reactive oxygen metabolites. Alterations produced by doxorubicin. J. Clin. Invest. 65: 128-135.

4. Burls, R. F., R. A. Lawrence, and M. M. Love. 1980. Liver necrosis and lipid peroxidation in the rat as a result of paraquot and diquot administration. Effect of selenium deficiency. J. Clin. Invest. 65: 1024-1031. 
5. Clark, R. A., and S. J. Klebanoff. 1975. Neutrophil-mediated tumor cell cytotoxicity: Role of the peroxidase system. J. Exp. Med. 141: 1442-1447.

6. Klebanoff, S. J., and R. A. Clark. 1975. Hemolysis and iodination of erythrocyte components by a myeloperoxidase-mediated system. Blood. 45: 699-707.

7. Rosen, H., and S. J. Klebanoff. 1977. Formation of singlet oxygen by the myeloperoxidase-mediated antimicrobial system. J. Biol. Chem. 252: 4803-4810.

8. Kellogg, E. W., and I. Fridovich. 1977. Liposome oxidation and erythrocyte lysis by enzymatically generated superoxide and hydrogen peroxide. J. Biol. Chem. 252: $6721-6728$

9. Nathan, C. F., L. Brukner, S. C. Silverstein, and Z. A. Cohn. 1979. Extracellular cytolysis by activated macrophages and granulocytes. J. Exp. Med. 149: 100-113.

10. Hafeman, D. D., and Z. J. Lucas. 1979. Polymorphonuclear leukocyte mediated antibody dependent cellular cytotoxicity against tumor cells. Dependence on oxygen and the respiratory burst. J. Immunol. 123: 55-62.

11. Weiss, S. J., P. K. Ruitagi, and A. F. LoBuglio. 1978. Human granulocyte generation of hydroxyl radical. J. Exp. Med. 147: 316-323.

12. Thorne, K. J., R. J. Svvensen, and D. Franko. 1980. Role of hydrogen peroxide in the cytotoxic reaction of $\mathrm{T}$ lymphocytes. Clin. Exp. Immunol. 39: 486-495.

13. Petrone, W. F., D. K. English, K. Wong, and J. M. McCord. 1980. Free radicals and inflammation: The superoxide dependent activation of a neutrophil chemotactic factor in plasma. Proc. Natl. Acad. Sci. U. S. A. 77. 1159-1163.

14. McCormick, J. R., M. M. Harkin, K. J. Johnson, and P. A. Ward. The effect of superoxide dismutase on pulmonary and dermal inflammation. Am. J. Pathol. In press.

15. Salin, M. L., and J. M. McCord. 1974. Superoxide dismutases in polymorphonuclear leukocytes.J. Clin. Invest. 54: 1005-1009.

16. Thurman, R. G., H. G. Ley, and R. Scholz. 1972. Hepatic microsomal ethanol oxidation. Hydrogen peroxide formation and the role of catalase. Eur.J. Biochem. 25: 420-430.

17. Means, G. E., and R. E. Feeney. 1971. In Chemical Modifications of Proteins. Holden-Day, Inc., San Francisco, Calif. 217.

18. Beers, R. F., and I. W. Sizer. 1952. A spectrophotometric method for measuring the breakdown of hydrogen peroxide by catalase. J. Biol. Chem. 195: 133-140.

19. Johnson, K. J., and P. A. Ward. 1974. Acute immunologic pulmonary alveolitis. J. Clin. Invest. 54: 349-352.

20. Rosen, H., and S. J. Klebanoff. 1979. Hydroxyl radical generation by polymorphonuclear leukocytes measured by electron spin resonance spectroscopy. J. Clin. Invest. 64: 1725-1729.
21. Morrison, M. 1970. Iodination of tyrosine, isolation of lactoperoxidase. Methods Enzymol. 17: H. Tabor and C. W. Tabor, editors. Academic Press, Inc., New York. 653.

22. Klebanoff, S. J. 1975. Antimicrobial mechanism in neutrophilic polymorphonuclear leukocytes. Sem. Hematol. 12: 117-142.

23. Lynch, R. E., and I. Fridovich. 1978. Effects of superoxide on the erythrocyte membrane. J. Biol. Chem. 253: $1838-1845$.

24. Weiss, S. J., A. F. LoBuglio, and H. B. Kessler. 1980. Oxidative mechanisms of monocyte mediated cytotoxicity. Proc. Nat. Acad. Sci. U. S. A. 77: 584-587.

25. Weiss, S. J. 1979. Neutrophil generated hydroxyl radicals destroy RBC targets. Clin. Res. 27: 466A. (Abstr.)

26. Sachs, T., C. F. Moldow, P. R. Craddock, J. K. Bowers, and H. S. Jacob. 1978. Oxygen radical mediated endothelial cell damage by complement-stimulated granulocytes. An in vitro model of immune vascular damage. J. Clin. Invest. 61: $1161-1167$.

27. Janoff, A., R. White, H. Carp, S. Harel, R. Dearing, and D. Lee. 1979. Lung injury induced by leukocytic protease. Am. J. Pathol. 97: 111-130.

28. Ward, P. A., and J. H. Hill. 1972. Biological role of complement products. Complement derived leukotactic activity extractable from lesions of immunologic vasculitis. J. Immunol. 135: 1095-1103.

29. Johnson, K. J., J. Varani, J. Oliver, and P. A. Ward. 1979. Immunologic vasculitis in beige mice with deficiency of leukocytic neutral protease. J. Immunol. 122: 1807-1811.

30. Becker, E. L., M. Sigman, and J. M. Oliver. 1979. Superoxide production induced in rabbit polymorphonuclear leukocytes by synthetic chemotactic peptides and A23187. Am. J. Pathol. 95: 81-97.

31. Desai, U., D. L. Kreutzer, H. Showell, C. V. Arroyave, and P. A. Ward. 1979. Acute inflammatory pulmonary reactions induced by chemotactic factors. Am. J. Pathol. 96: $71-83$.

32. Curnutte, J. T., and B. M. Babior. 1974. Biologic defense mechanisms. The effects of bacteria and serum on superoxide production by granulocytes. J. Clin. Invest. 53: $1662-1674$.

33. Root, R. K., J. Metcalf, W. Oshino, and B. Chance. 1975. $\mathrm{H}_{2} \mathrm{O}_{2}$ release from human granulocytes during phagocytosis. I. Documentation, quantitation and some regulating factors. J. Clin. Invest. 55: 945-955.

34. Hunninghake, G. W., J. E. Gadek, O. Kawanami, V. J. Ferrous, and R. G. Crystal. 1979. Inflammatory and immune processes in human lung in health and disease: Evaluation by branchoalveolar lavages. Am. J. Pathol. 97: 149-206. 